\title{
Penguatan eksistensi kota kreatif melalui inovasi desain kamuflase menara BTS berbasis zonasi wilayah
}

\author{
Nor Jayadi, ${ }^{1 *}$ Rahmawan Dwi Prasetya ${ }^{1}$ \\ ${ }^{1}$ Program Studi Desain Produk, Institut Seni Indonesia Yogyakarta, Indonesia
}

\begin{abstract}
This paper discusses an effort to maintain and strengthen the existence of Yogyakarta City as a creative city through the innovation of communication infrastructure in the form of BTS (Base Transceiver Station) tower by offering the idea of camouflage design of BTS tower based zonation area that has been determined in Yogyakarta City Local Regulation No. 1 of 2015 about Spatial Detail Plan and Zoning Regulation of Yogyakarta City 2015 - 2035. Besides being driven by the importance of communication aspect which is one of important elements in creative city, the design innovation is also expected to show the concern of all stakeholders about the importance of harmonization and aesthetics in a city area.
\end{abstract}

Key words: BTS tower, camouflage, creative city

\begin{abstract}
Abstrak
Tulisan ini membahas sebuah upaya untuk mempertahankan dan menguatkan eksistensi Kota Yogyakarta melalui inovasi infrastruktur komunikasi berupa menara BTS (Base Transceiver Station) dengan menawarkan ide desain kamuflase menara BTS yang berbasis zonasi wilayah yang telah ditentukan dalam Peraturan Daerah Kota Yogyakarta Nomor 1 Tahun 2015 tentang Rencana Detail Tata Ruang Dan Peraturan Zonasi Kota Yogyakarta Tahun 2015 - 2035. Selain karena didorong oleh kepentingan aspek komunikasi yang merupakan salah satu unsur penting dalam kota kreatif, inovasi desain tersebut juga diharapkan dapat menunjukkan kepedulian seluruh stakeholder akan pentingnya harmonisasi dan estetika dalam sebuah wilayah kota.
\end{abstract}

Kata kunci: menara BTS, kamuflase, kota kreatif

\section{Pendahuluan}

Sebuah kota modern adalah kota yang mampu menyesuaikan diri dengan perkembangan jaman. Kata 'moderen' dalam hal ini tidak berarti mengabaikan apa yang sudah eksis di sebuah kota tetapi lebih ke bagaimana cara mengantisipasi berbagai perkembangan. Perkembangan tersebut meliputi berbagai hal, seperti perkembangan ekonomi, teknologi, sosial dan budaya. Kota moderen seharusnyalah memiliki kemampuan untuk mengakomodasi berbagai perkembangan dengan menyediakan fasilitas-fasilitas yang memadai, yang dapat dimanfaatkan penduduknya secara optimal. Mengantisipasi kondisi tersebut pemerintah kota berkewajiban tidak hanya menyediakan tapi juga merencanakan pengembangan-pengembangan untuk kebutuhan saat ini dan di masa depan. Kota
Yogyakarta sebagai salah satu kota besar di Indonesia dengan berbagai predikat yang dimilikinya, yaitu kota pendidikan, kota budaya, wisata dan kota sejarah tentu saja harus responsif terhadap berbagai perkembangan jaman.

Salah satu predikat lain yang disematkan pada kota Yogyakarta adalah Kota Kreatif. Bekraf (Badan Ekonomi Kreatif) pada tahun 2017 telah menobatkan Kota Yogyakarta sebagai kota kreatif nomer 3 setelah Pekalongan dan Bandung. Mengapa disebut sebagai Kota Kreatif? Girard, Baycan, \& Nijkamp (2011) menyebut istilah kota kreatif secara umum dipahami dan digunakan dalam empat hal, yaitu : (a) kota kreatif sebagai focal point infrastruktur seni dan budaya, (b) kota kreatif sebagai tempat aksi ekonomi kreatif, (c) kota kreatif identik dengan masyarakatnya yang kreatif, dan (d) sebuah kota kreatif sebagai tempat yang menumbuhkan budaya kreativitas. Di

\footnotetext{
* Koresponden penulis e-mail : norjayadi75@gmail.com
} 
kota-kota kreatif, kebanyakan strategi berkaitan dengan penguatan seni dan budaya. Warisan seni dan budaya, industri media dan hiburan, dan layanan bisnis-ke-bisnis kreatif adalah pendorong inovasi dalam ekonomi kreatif. Terjadi persaingan untuk menarik, mempertahankan atau mengembangkan kelas kreatif mereka sendiri, sementara faktor-faktor yang berkontribusi terhadap hal ini seperti 'kualitas tempat' sangat penting, dan ada sistem terpadu dari berbagai organisasi dan gabungan budaya di sektor publik, swasta dan masyarakat. Kota kreatif diharapkan dapat mengembangkan solusi imajinatif dan inovatif untuk berbagai masalah sosial, ekonomi dan lingkungan: stagnasi ekonomi, penyusutan perkotaan, segregasi social dan persaingan global .

\section{Pembahasan}

Secara lebih jelas bagan tentang kota kreatif seperti disampaikan oleh Girard, Baycan, \& Nijkam (2011) adalah sebagai berikut:

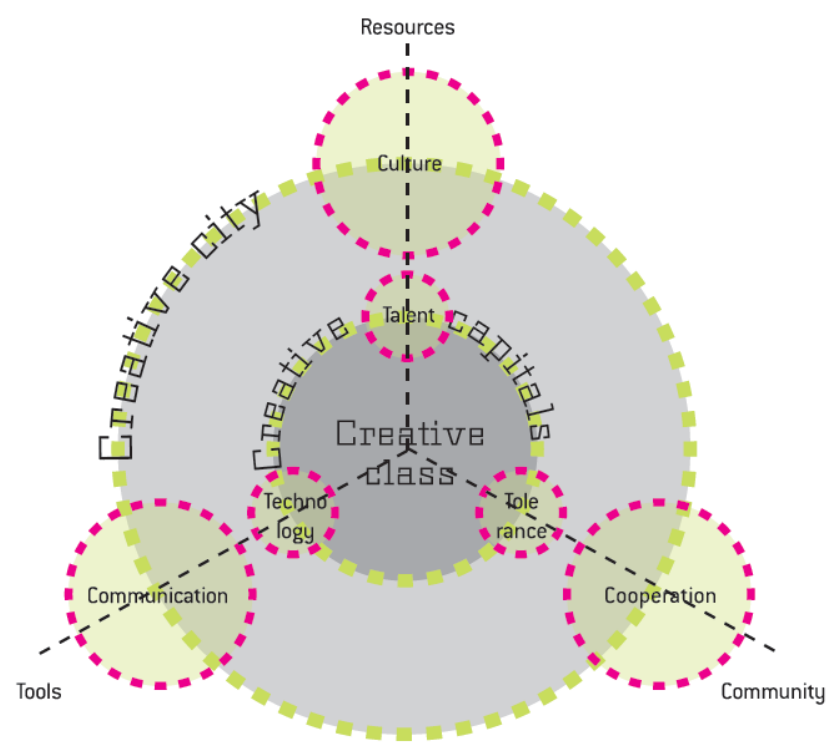

Gambar 1. Bagan kota kreatif (Girard et al., 2011)

Selanjutnya, Carta (2007) menyebut bahwa daya saing kota kreatif tergantung pada 3 faktor, yaitu budaya, komunikasi dan kerjasama. Budaya dalam hal ini adalah identitas kota yang memiliki kesejarahan namun juga berkembang ke masa depan. Identitas sebuah kota juga harus menghasilkan nilai yang diaktualisasikan dalam aspek-aspek kehidupan masyarakatnya. Budaya, oleh karena itu berperan dalam bidang sumber daya yang memungkinkan kota menjadi lebih kreatif. Faktor kedua dari kreativitas kota adalah komunikasi, yaitu kemampuan kota dalam berbagi informasi dengan melibatkan secara real time warganya. Penggunaan teknologi komunikasi memungkinkan intervensi yang mungkin dilakukan untuk mengurangi berbagai problem perkotaan. Kota yang memanfaatkan teknologi inovasi secara efektif juga akan yang mempermudah mobilitas, memperbaiki cara warganya beraktivitas, pelayanan pemerintah kota dan kemudahan-kemudahan lainnya. Adapun faktor ketiga adalah kerjasama, yaitu yang menyiratkan kemampuan untuk mengumpulkan serangkaian komponen, memfokuskan tindakan pada tujuan dan hasil yang sama. Kota kreatif bukan hanya kota yang lebih terbuka, multikultural dan multietnis, kota ini juga mampu memobilisasi beragam komponennya dalam mengejar rencana masa depan. Ketiga faktor tersebut, yaitu budaya, komunikasi dan kerjasama adalah sumber penting bagi pemerintah kota untuk membuat perencanaan kota yang dapat berkontribusi terhadap kebahagiaan keseluruhan masyarakat yang ingin mereka layani.

Berdasar penjelasan di atas salah satu kebutuhan utama penduduk suatu kota yang akan dibahas dalam tulisan ini adalah kemudahan dalam berkomunikasi. Pemerintah kota sejauh ini sudah melakukan berbagai program dalam rangka mengembangkan solusi-solusi untuk pemenuhan kebutuhan komunikasi warganya. Komunikasi yang dimaksud adalah tidak hanya berupa komunikasi tatap muka saja tetapi juga komunikasi menggunakan bantuan teknologi, yaitu komunikasi telepon. Tidak dapat dipungkiri komunikasi telepon berkembang dengan amat pesat, terutama yang berlangsung saat ini adalah telepon nirkabel atau telepon selular. Sudah bukan jamannya lagi bertelepon dengan hanya mendengarkan suara tetapi dengan kemajuan teknologi bertelepon juga dapat sambil melihat lawan bicara. Telepon tidak hanya untuk saling berbicara karena dengan telepon selular pengguna dapat menggunakan layanan data untuk berselancar sesuai kebutuhannya.

Penggunaan layanan ini tidak hanya untuk telepon selular saja tetapi juga digunakan untuk gawai-gawai lain yang semakin beragam macamnya. Khusus untuk pengguna selular jumlahnya berkembang dengan sangat pesat karena teknologi yang ditawarkan tersebut. Pada tahun 2015, dari tiga operator utama di Indonesia, yaitu Indosat, XL dan Tekomsel jumlah pelanggannya masing-masing adalah sebesar 66,5 juta pelanggan untuk Indosat, 52,1 juta pelanggan untuk XL dan terbanyak adalah Telkomsel dengan 140 juta pelanggan. Selanjutnya untuk menjangkau jumlah pelanggan sebanyak itu di seluruh Indonesia Indosat membangun 40.756 BTS, XL walaupun jumlah pelanggannya lebih kecil membangun 52.000 BTS 
dan paling banyak adalah Telkomsel yang membangun 90.000 BTS (Noor, 2015).

Menara BTS sendiri merupakan satu infrastruktur telekomunikasi yang sangat vital. Secara umum, ada 3 jenis menara BTS berdasarkan jenis konstruksinya (Arjanggi, Wahyuni, \& Soewardojo, 2012), yaitu Self Supporting Tower kaki empat, Self Supporting Tower kaki tiga (Gambar 2) dan Monopole Tower (Gambar $3)$.

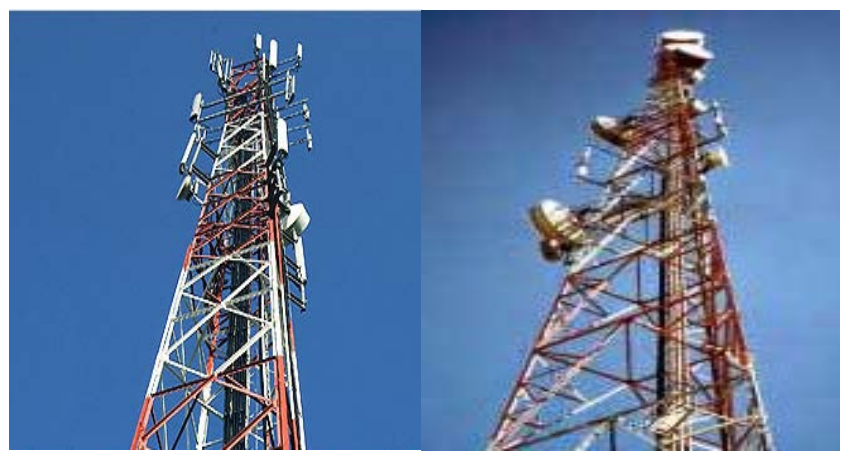

Gambar 2. Menara Kaki Empat dan Menara Kaki Tiga Sumber: http://poskotanews.com/cms/wpcontent/uploads/2014/02/menara.jpg https://i1.wp.com/www.inmexedu.com/wpcontent/uploads/2017/08/Triangle-Tower.jpg?resize=322\%2C429

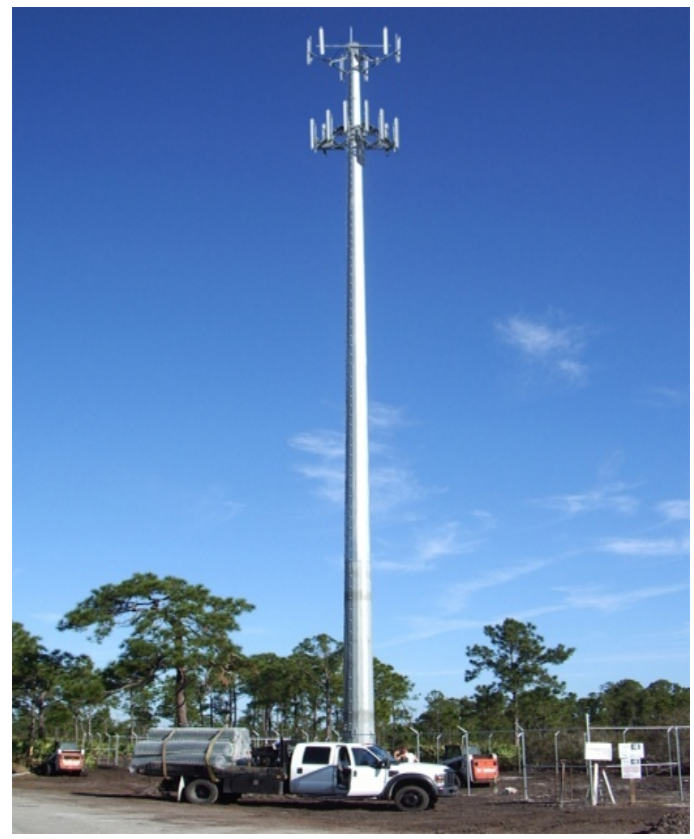

Gambar 3. Menara Monopole

Berdasar data tersebut terlihat bahwa pembangunan infrastruktur menara BTS masing-masing operator cukup masif. Tugas pemerintah adalah memayunginya dengan aturan perundang-undangan agar semua dapat tertata dengan baik. Di Kota Yogyakarta aturan ini tertuang dalam Peraturan
Daerah Kota Yogyakarta Nomor 1 Tahun 2015 tentang Rencana Detail Tata Ruang Kota Yogyakarta. Penataan sangat penting dilakukan karena seringkali terjadi masalah pada pembangunan menara BTS, baik yang bersifat teknis maupun non teknis. Seperti diungkapkan oleh Fauzi yang menyebutkan bahwa lokasi penempatan menara memang menjadi sesuatu yang krusial dan harus sesuai dengan kepentingan bisnis yang selaras dengan aspek regulasi (Widyatmoko \& Mauludiyanto, 2015). Pembangunan menara BTS seharusnya memang menyesuaikan diri dengan Rencana Detail Tata Ruang Kota Yogyakarta, yang secara terinci sudah dibagi menjadi beberapa zona sesuai peruntukan dan ciri khasnya, yaitu :

a. Zona Lindung yang terdiri dari: (a) Zona Suaka Alam dan Cagar Budaya (SC); (b) Zona Ruang Terbuka Hijau (RTH) kota; dan (c) Zona Perlindungan Setempat (PS).

b. Zona budidaya yang terdiri dari: (a) Zona Perumahan (R); (b) Zona Perdagangan dan Jasa (K); (c) Zona Perkantoran (KT); (d) Zona Sarana Pelayanan Umum (SPU); (e) Zona Industri (I); dan (f) Zona Peruntukan Lain (PL).

Tujuan pembagian wilayah kota berdasarkan zonazona tertentu adalah agar pemerintah lebih mudah dan fokus dalam menjalankan program-programnya, baik program kependudukan maupun program pembangunan yang bersifat fisik. Berikut adalah contoh nukilan gambar pembagian zona di sebagian wilayah kota Yogyakarta berdasarkan Peraturan Daerah Kota Yogyakarta Nomor 1 Tahun 2015 Tentang Rencana Detail Tata Ruang Dan Peraturan Zonasi Kota Yogyakarta Tahun 2015 - 2035.

Contoh gambar zonasi sebagian wilayah dalam kota Yogyakarta tampak pada Gambar 4 yang menunjukkan pembedaan yang cukup rinci, walaupun pada kenyataannya banyak wilayah yang kurang sesuai dengan peruntukannya. Masalah klasik di perkotaan adalah terdapat keterbatasan lahan dan ketersinggungan langsung dengan aktivitas masyarakat jika akan dibangun infrastruktur baru, yang dalam studi ini adalah menara BTS. Kondisi demikianlah yang menuntut operator mencari cara agar mereka tetap dapat membangun menara BTS dalam rangka memenuhi pesatnya pertumbuhan pengguna seluler. Salah satu cara mengatasi masalah yang sekarang mulai banyak dilakukan operator adalah dengan membuat desain kamuflase untuk menara BTS.

Apakah menara BTS kamuflase itu? Dikatakan 'kamuflase' karena menara BTS tersebut tidak 
tampak eksistensinya secara vulgar sebagai menara yang menjulang di sebuah kawasan. Benda yang dikamuflase adalah benda yang disamarkan keberadaannya. Benda tersebut menyatu secara visual dengan lingkungannya.
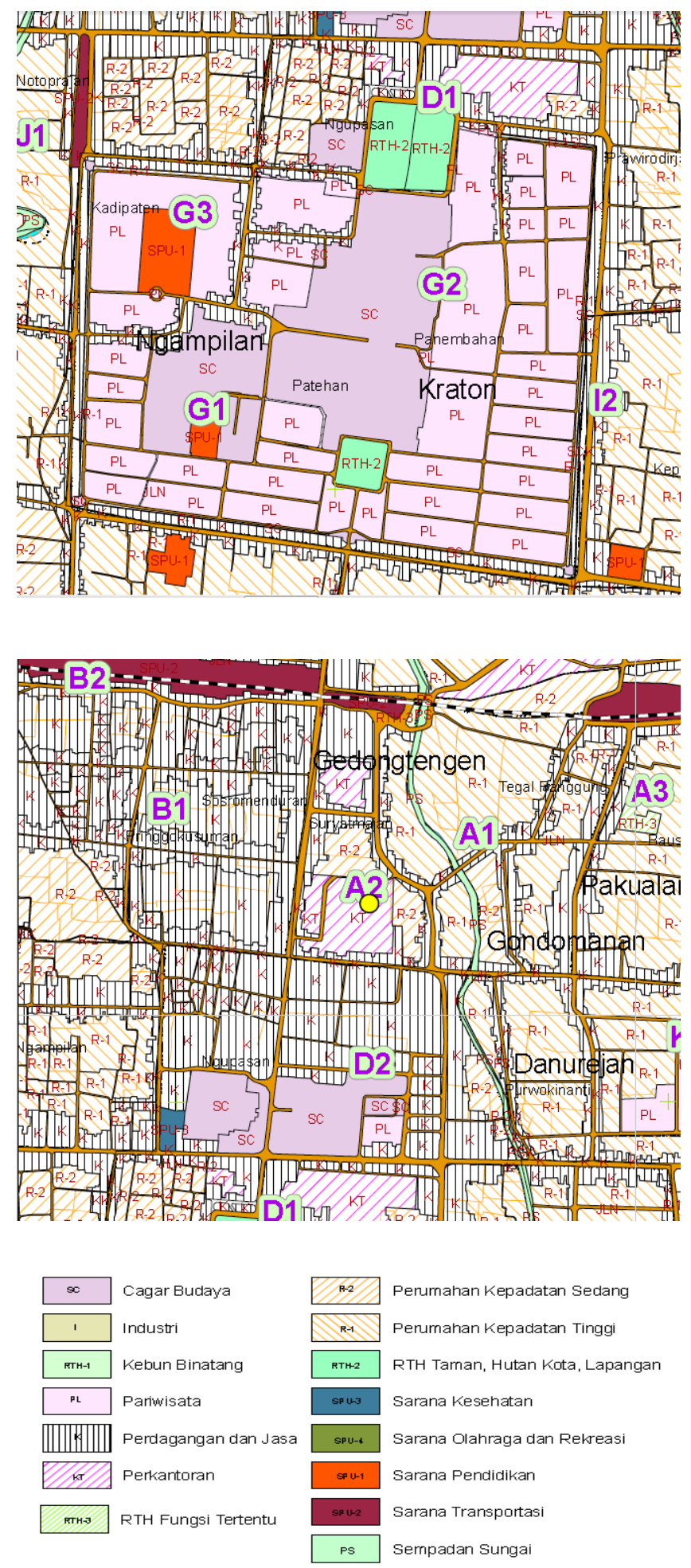

Gambar 4. Zonasi wilayah Kraton dan sekitarnya (atas) dan wilayah Malioboro dan sekitarnya (bawah)

Sumber: Perda Kota Yogyakarta No. 1 Thn 2015
Dalam hal desain menara BTS, tujuan perancangan adalah 'menghilangkan' keberadaan menara BTS tersebut dengan menyamarkan bentuk visualnya. Penyamaran tersebut dapat berakibat menara BTS 'hilang' dan menyatu dengan lingkungannya. Akan tetapi kadang-kadang sekalipun 'hilang', menara BTS berubah menjadi benda yang justru menonjol secara visual dan justru monumental, hanya saja eksistensinya sebagai menara BTS telah hilang. Jenis menara BTS yang lazim di-kamuflase adalah jenis monopole (Gambar 3).

Menara BTS kamuflase dipandang sebagai solusi yang cukup menjanjikan karena desainnya dapat dirancang sedemikian rupa supaya lebih mudah menyesuaikan dengan lingkungan. Penelitian terdahulu, yang dilakukan dengan mengangkat kota metropolitan Jakarta dan Surabaya sebagai kasusnya, menawarkan beberapa alternatif desain antara lain berupa monumen kota, lampu kota, menara jam kota, menara masjid/gereja, city signage, dan landmark (Windharto \& Setiawan, 2009). Pertanyaan yang kemudian muncul dalam studi ini adalah 'apakah ciri zona di wilayah perkotaan dapat menjadi sumber ide kreatif untuk mendesain menara BTS kamuflase?'

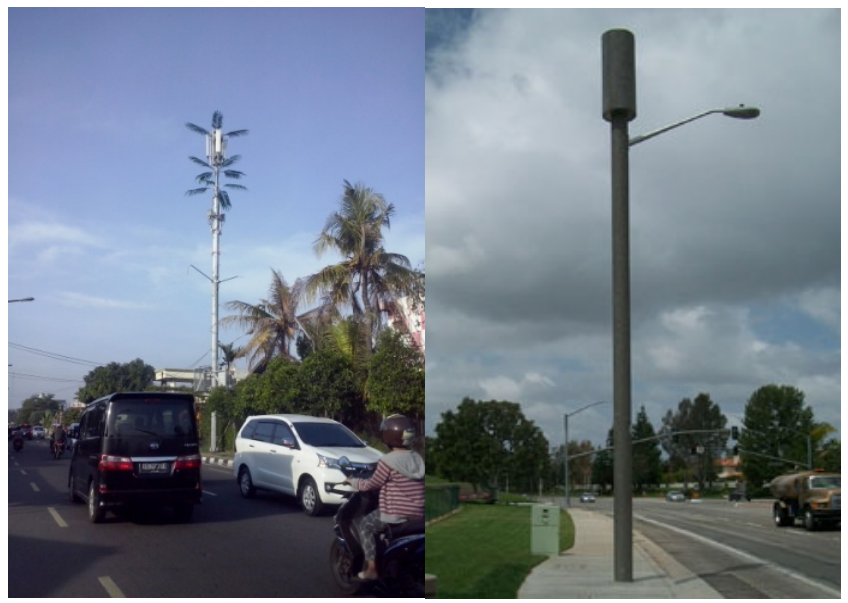

Gambar 5. Menara BTS yang di-kamuflase menjadi pohon (kiri) dan lampu jalan (kanan)

Dengan persyaratan teknis tertentu desain kamuflase pada menara BTS dapat dikembangkan sedemikian rupa sesuai dengan kebutuhan. Penggunaan ciri zona sebagai sumber ide kreatif desain kamuflase menara BTS didasarkan pada pemikiran bahwa pengembangan desain kamuflase tetap harus dibatasi agar kesesuaian dengan lingkungan relatif dapat terjaga. Sistem zonasi perkotaan sebagian disusun berdasar ciri yang sudah ada sebelumnya, sehingga dipandang dapat dijadikan sumber dari ide-ide kreatif reka rupa desain kamuflase menara BTS. Yogyakarta sebagai kota kreatif, yang 
Nor Jayadi \& Rahmawan Dwi Prasetya

Penguatan eksistensi kota kreatif melalui inovasi desain kamuflase menara BTS berbasis zonasi wilayah

sarat dengan laku dan peristiwa budaya, yang juga sebagai kota pendidikan dan kota wisata tentu tidak akan kekurangan ide dan bahan untuk mengembangkan berbagai desain menara kamuflase. Zona dalam kota Yogyakarta yang memang sudah dikembangkan sesuai dengan cirinya masing-masing dapat menjadi sumber ide kreatif desain tersebut. Hal yang menarik adalah dengan desain yang bersifat lokal maka akan lebih tepat jika yang melaksanakannya adalah desainer lokal, bahkan jika memungkinkan proses pengerjaannya juga melibatkan industri lokal. Bekraf (2017) bahkan menyebutkan bahwa keunggulan Yogyakarta terletak pada kekuatan industri kerajinan mereka, dan kemampuan budayawan dalam seni pertunjukan yang juga menjadi nilai lebih. Kreativitas sudah mengakar di kalangan warga Yogyakarta, kesederhanaan dalam ide dan menyelesaikan masalah merupakan ciri warga kota ini.

Berdasar pendapat tersebut dapat dilihat bahwa proses desain menara BTS kamuflase sebenarnya juga mampu dikerjakan oleh desainer lokal bekerja sama dengan bidang lain yang terkait, yang berasal dari lokal kota Yogyakarta juga. Proses pengerjaan desain menara BTS kamuflase memang tidak sederhana karena harus melalui beberapa tahapan yang menyertakan berbagai bidang disiplin, yang mana sumber daya tersebut sebenarnya sudah tersedia di kota Yogyakarta. Secara lebih rinci Windharto dan Setiawan menyebutkan tahap-tahap pembangunan menara BTS kamuflase adalah (Windharto \& Setiawan, 2009) :

a. Stage 1: Technology acquiring for digital design prototyping and city landscape study.

b. Stage 2: Implementation in prototyping, preproduction,publication and patent.

c. Stage 3: To do manufacturing and commercialization, produce publication and patent, formulating economic added value, application in form of regulation and public rule advices.

Berdasar tahapan tersebut dapat dilihat bahwa pada setiap tahapan fungsi desain produk mempunyai andil yang cukup signifikan. Kondisi demikian disebabkan oleh bangunan menara BTS yang jika di-kamuflase menjadi tidak berbentuk seperti menara BTS pada umumnya, tetapi ada unsur kreativitas yang kental mewarnai. Unsur kreativitas inilah yang kemudian dikolaborasikan dengan unsur-unsur lain dalam proses desain menara BTS kamuflase. Bertujuan agar unsur kreativitas dapat diwujudkan menjadi desain yang baik maka diperlukan kriteria-kriteria yang selanjutnya dapat digunakan sebagai pedoman melakukan desain.

Jayadi dan Prasetya menyebutkan bahwa terdapat 5 (lima) kriteria pengembangan desain menara kamuflase (Jayadi \& Prasetya, 2017), yaitu:

a. Friendly design. Diperlukan dialog antara masyarakat dengan stake holder pembangunan menara kamuflase agar muncul kedekatan antara masyarakat dengan desain kamuflase yang akan digunakan pada menara BTS.

b. Proporsional. Ukuran yang tidak terlalu besar atau tinggi sehingga tidak terlalu mencolok dibanding bangunan-bangunan di sekitarnya.

c. Aman. Bahan yang akan digunakan pada desain kamuflase harus yang relatif aman bagi lingkungan, termasuk dalam hal ini jika dihadapkan pada tantangan cuaca. Kriteria ini penting mengingat ukuran menara yang tidak besar dan tinggi serta benar-benar berada dekat dengan masyarakat yang beraktivitas.

d. Redesign. Rancangan desain dapat memanfaatkan bangunan yang sudah ada, baik bangunan menara monopole yang sudah eksisting atau bangunan lain yang secara teknis memenuhi syarat untuk 'ditempeli' menara kamuflase. Kelebihan dari rancangan seperti ini adalah penghematan dari sisi ketersediaan lokasi dan untuk menghindarkan investasi baru yang besar.

e. Tematik. Berbagai desain inovatif dapat dikembangkan sesuai dengan ciri khas lingkungan sekitarnya, yang mana ciri khas tersebut bersumber dari sistem zonasi yang diterapkan di lingkungan perkotaan.

\section{Kesimpulan}

Kriteria di atas sudah selayaknya menjadi tantangan bagi stake holder menara BTS kamuflase, terutama yang berasal dari lokal kota Yogyakarta untuk memanfaatkan sumber dayanya membangun menara BTS kamuflase dengan berwarnakan ciri khas lokal. Ciri khas lokal mempunyai kekuatan sendiri untuk menguatkan daya saing sebuah kota, yang dalam studi ini adalah daya saing yang mengandalkan kreativitas. Sistem pembagian zonasi kota dinilai dapat menjadi sumber ide kreatif untuk mewujudkan menara BTS kamuflase, sekaligus sebagai batasan agar pembangunan menara BTS kamuflase tetap dapat menyesuaikan dengan lingkungannya. Pengembangan desain kamuflase menara BTS berbasis zonasi perkotaan tersebut dapat berpotensi 
untuk menguatkan eksistensi Kota Yogyakarta sebagai kota kreatif yang unik.

Langkah lanjutan yang perlu dilakukan adalah melakukan studi perancangan kamuflase menara BTS yang berdasarkan 5 kriteria desain tersebut yang disesuaikan dengan zonasi wilayah tertentu di Kota Yogyakarta. Dengan melibatkan para desainer produk, output yang diharapkan adalah inovasi desain kamuflase menara BTS yang sesuai dengan lingkungannya.

\section{Daftar pustaka}

Arjanggi, S., Wahyuni, E., \& Soewardojo. (2012). Studi Perbandingan Struktur Tower BTS Tipe SST Kaki 4, SST Kaki 3 dan Monopole dengan Ketinggian 40m yang Paling Effisien. Jurnal Teknik POMITS, 1(1), 1-5.

Bekraf. (2017). 10 Kota Kreatif di Indonesia. Retrieved November 2, 2017, from http://indonesiakreatif.bekraf.go.id/iknews/10-kota-kreatif-diindonesia-2/

Carta, M. (2007). Creative City: Dynamics, Innovations, Actions. Barcelona:

ActarD. https://doi.org/10.1017/CBO9781107415324.004

Girard, L. F., Baycan, T., \& Nijkamp, P. (2011). Sustainable city and creativity. Burlington: Ashgate Publishing Company.

Jayadi, N., \& Prasetya, R. D. (2017). Persepsi masyarakat terhadap desain kamuflase menara BTS di lingkungan perkotaan Studi kasus: Kota Yogyakarta. In International Symposium of Art, Craft, and Design in Southeast Asia (pp. 77-98). Yogyakarta. Retrieved from https://www.researchgate.net/publication/321148943_Persepsi _Masyarakat_terhadap_Desain_Kamuflase_Menara_BTS_di_ Lingkungan_Perkotaan_Studi_Kasus_Kota_Yogyakarta

Noor, A. R. (2015). Indosat Salip XL, Juaranya Masih Telkomsel. Retrieved from https://inet.detik.com/telecommunication/d2944604/indosat-salip-xl-juaranya-masih-telkomsel

Widyatmoko, \& Mauludiyanto, A. (2015). Perencanaan Jumlah dan Lokasi Menara Base Transceiver Station (BTS) Baru pada Telekomunikasi Seluler di Kabupaten Lumajang Menggunakan Metode Analytical Hierarchy Process-TOPSIS (AHP-TOPSIS). Jurnal Teknik ITS, 4(1), 71-76.

Windharto, A., \& Setiawan, A. (2009). Multi Operator BTS Aesthetic Tower Design for Metropolitan City. In Proceedings of the 1st CIRP Industrial Product-Service Systems (IPS2) Conference, Cranfield University (pp. 8-15). Cranfield: Cranfield University. 